\title{
Lymphatic Drug Absorption via the Enterocytes: Pharmacokinetic Simulation, Modeling, and Considerations for Optimal Drug Development
}

\author{
Dion R. Brocks and Neal M. Davies
}

Faculty of Pharmacy and Pharmaceutical Sciences, University of Alberta, Edmonton, AB, Canada. Faculty of Pharmacy \& Pharmaceutical Sciences, 2142J Katz. Group-Rexall Centre for Pharmacy and Health Research, University of Alberta, Edmonton, Alberta, Canada.

Received, September 14, 2018; Accepted, October 17, 2018 Published, October 222018.

\begin{abstract}
Most orally administered drugs gain access to the systemic circulation by direct passage from the enterocyte layer of the intestinal tract to the mesenteric blood capillaries. Intestinal lymphatic absorption is another pathway that certain drugs may follow to gain access to the systemic circulation after oral administration. Once absorbed, drug diffuses into the intestinal enterocyte and while in transit may associate with fats as they are processed into chylomicrons within the cells. The chylomicron-associated drug is then secreted from the enterocyte into the lymphatic circulation, thus avoiding the hepatic first-pass liver metabolism, and ultimately entering to the systemic circulation for disposition and action. Due to the possibility of parallel and potentially alternative absorptive pathways, mesenteric blood capillary and lymphatic drug exposure are both potential pathways of systemic availability for any individual drug. In this report, an in silico modeling approach was adopted to delineate the salient pharmacokinetic features of lymphatic absorption, and provide further guidance for the rationale design of drugs and drug delivery systems for lymphatic drug transport. The importance of hepatic extraction ratio, absorption lag time, lipoprotein binding, and the influence of competing portal and lymphatic pathways for systemic drug availability were explored using simulations. The degree of hepatic extraction was found to be an essential consideration when examining the influence of lymphatic uptake to overall oral drug bioavailability. Lymphatic absorption could potentially contribute to multiple peaking phenomena and flip flop pharmacokinetics of orally administered drugs.
\end{abstract}

\section{INTRODUCTION}

Orally administered xenobiotics, including drugs, generally enter the systemic circulation after passing through small intestinal enterocytes, followed by movement through the hepatic portal circulation (Figure 1). However, an additional pathway for oral entry into the post-portal hepatic circulation exists. With this process, xenobiotic in the enterocytes may associate with lipoproteins, specifically chylomicrons, as lipids are processed during their absorption from the gastrointestinal tract. Xenobiotic within the lymph, most likely chylomicronassociated, is subsequently secreted into the mesenteric lymphatic circulation, rather than the hepatic portal circulation. The drug in mesenteric lymph then passes into the thoracic duct and later systemically circulates in the vasculature in the posthepatic systemic circulation. Drugs that are transported via the lymphatics thus can also increase drug concentrations systemically and increase exposure in lymph ducts and nodes. Notably, the lymphatic pathway can circumvent hepatic first pass extraction which can potentially lead to a higher level of bioavailability than if it were to only pass through the portal pathway (Figure 1).

Many existing drugs are synthesized with physicochemical characteristics $(\log \mathrm{P}>5$, triglyceride solubility $>50 \mathrm{mg} / \mathrm{mL}$, or large molecular weight $>500 \mathrm{~g} / \mathrm{mol}$ ) that are potentially suitable for lymphatic transport through lacteals. Others may also be under development or being formulated with lymphatic absorption and uptake as a target ${ }^{1-3}$. However, the salient pharmacokinetic factors underlying lymphatic uptake and resultant systemic bioavailability and disposition have not been modelled and delineated using a rationalized pharmacokinetic approach.

The pharmaceutical industry is replete with computational and pharmacoinformatic approaches to oral bioavailability predictions. These softwarebased approaches assist in new chemical entity drug discovery and translation to clinical development.

Corresponding Author: Dion R. Brocks, Faculty of Pharmacy \& Pharmaceutical Sciences, 2142J Katz. Group-Rexall Centre for Pharmacy and Health Research, University of Alberta, Edmonton, Alberta, Canada. E-mail: dbrocks@ualberta.ca 
The importance of solubility and intestinal permeability is inherent in the Biopharmaceutical Classification System recognized in many of these software. There are now several sources for commercial ADME simulation software mainly focused on absorption and physiologically based pharmacokinetic modelling (i.e. GastroPlus ${ }^{\mathrm{TM}}$, Intellipharm ${ }^{\circledR} P K$ software, Simcyp ${ }^{\mathrm{TM}}$ Simulator, iDEA $^{\mathrm{TM}}$ software, PK-Sim ${ }^{\circledR}$, Cloe ${ }^{\circledR}$ PK and many others). However, we are not aware of currently available software utilized for ADME modeling that incorporate the factors regulating the lymphatic oral absorption and delivery of drugs. In fact, the importance and contribution of lymphatic absorption in drug development and the pharmacokinetic processes and factors that will determine the disposition profile of drugs that undergo lymphatic absorption have been, so far, mostly overlooked ${ }^{4,5}$.

To gain insight into the possible contribution of lymphatic absorption to systemic exposure of drug, here we discuss using pharmacokinetic factors (low, moderate, high extraction ratio), absorption lag time, one versus two compartmental open models, and lipoprotein binding with respect to enterocyte lacteal lymphatic absorption of drugs. The influence of competing portal and lymphatic pathways was also examined with simulations. This information can lead to a more rational design of drugs and delivery systems for enhancing lymphatic drug transport and the factors that affect their disposition.

\section{Simulating portal and lymphatic absorption}

There are several considerations involved in modelling the lymphatic absorption of drugs. One is the extent to which drug reaches the systemic circulation through the intestinal enterocyte to the lymphatics to post-hepatic blood transfer, versus direct intestinal enterocyte to hepatic portal blood transfer of drugs. In the experimental study of lymphatic absorption, one of the approaches is the mesenteric lymph-duct cannulated animals where lymphatic uptake is determined in surgical-diversion studies; this allows the complete collection of lymph flowing through the cannula. Having collected all of the lymph allows for an estimate of the total extent of lymphatic drug transport of a drug. However, available data indicates that drug still is able to be bioavailable through the portal vein into the systemic circulation, suggesting that both pathways are involved in the absorption and entry of drugs into the blood $^{6-9}$.

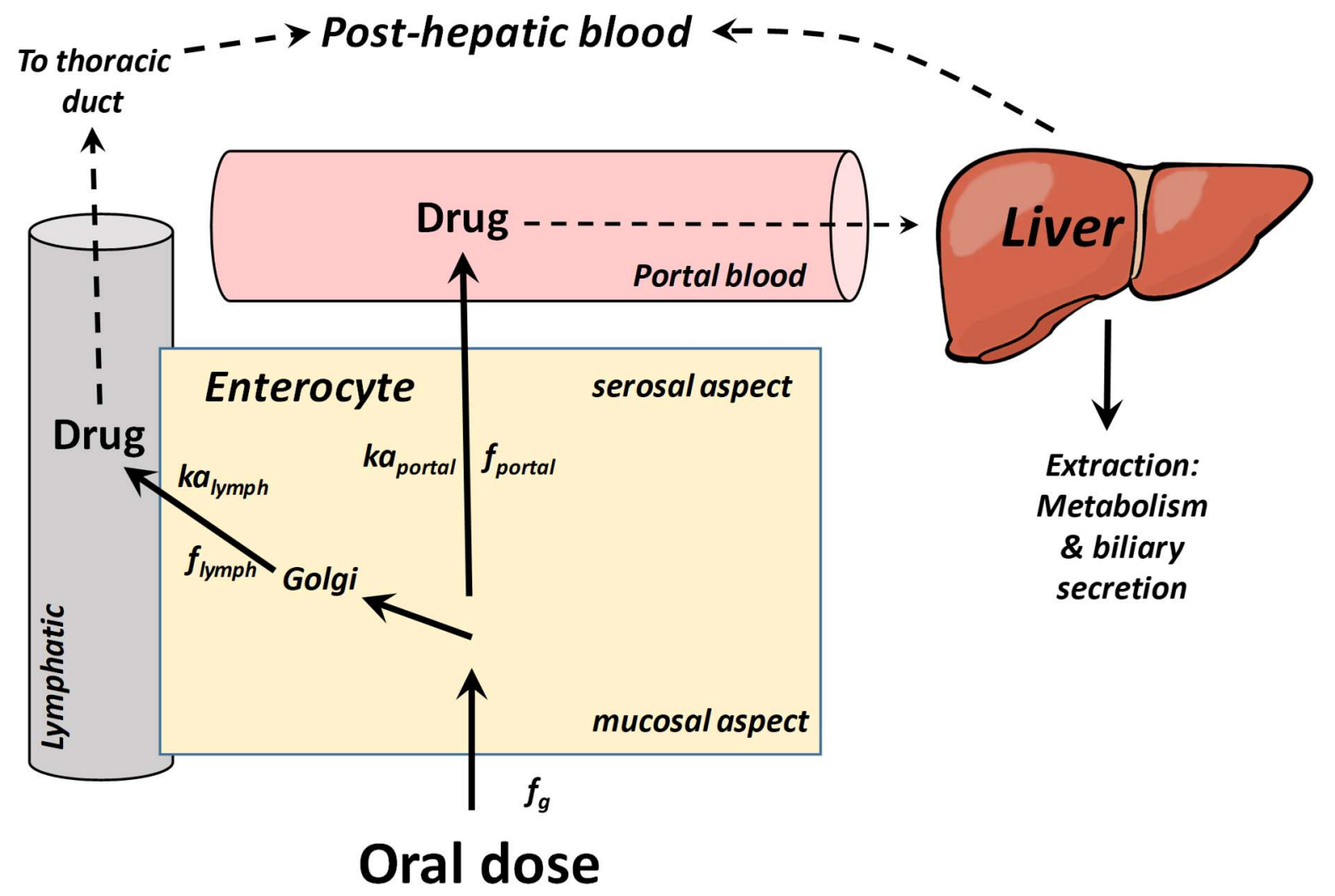

Figure 1. Pathways of drug movement into the systemic circulation 
Therefore, to permit a study of these pathways, a one and two compartment model was used to simulate drug disposition after oral dosing. The basic steps in movement of drug into the systemic circulation from the formulation in the gastrointestinal lumen to the post-hepatic circulation is depicted in Figures 1 and 2. Where they differ is in their distributional characteristics in the post-hepatic circulation (Figure 2).

In these simulations, the blood clearance (CL) of the drugs was assumed to be due to hepatic clearance, as follows:

$$
C L=\frac{Q \times f_{u} \times C L^{\prime}{ }_{\text {int }}}{Q+\left(f_{u} \times C L^{\prime}{ }_{\text {int }}\right)}
$$

Where $\mathrm{Q}$ is hepatic blood flow, $f_{u}$ is the unbound fraction in blood and $\mathrm{CL}^{\prime}$ int is the intrinsic clearance of the unbound drug. The basic value of $\mathrm{Q}$ was 90 $\mathrm{L} / \mathrm{h}$. to match the average value in humans ${ }^{10}$.

The steady-state volume of distribution was estimated as $V d=V_{\text {blood }}+V_{\text {app,tissues, }}$, where $\mathrm{V}_{\text {blood }}$ and $\mathrm{V}_{\text {app,tissue }}$ are the volumes of blood and that apparently in tissues, respectively. The latter term is expanded as $V d=V_{\text {blood }}+\frac{f_{u}}{f_{t}} \times V_{\text {tissues }}$, where $\mathrm{f}_{\mathrm{t}}$ is the unbound fraction in tissues and $\mathrm{V}_{\text {blood }}$ and $\mathrm{V}_{\text {tissues }}$ are the volumes of blood and tissues, respectively. The apparent tissue volume is $\frac{f_{u}}{f_{t}} \times V_{\text {tissues }}$.

The value of fraction of the dose absorbed from the gut $\left(f_{g}\right)$ is the sum of the fraction of the dose absorbed via the lymphatic and portal pathways $\left(f_{\text {lymph }}+f_{\text {portal }}\right)$. In its simplest form, each uptake pathway is independent of one another. The concentrations of drug in the blood is the sum of the concentrations imparted by appearance of drug in the systemic circulation through each of these two input processes. The disposition of drug by the one compartment model was estimated as follows:

$$
\begin{aligned}
C_{\text {blood }}=\frac{\text { Dose }}{V d} \times & {\left[\left(\frac{f_{\text {lymph }} \cdot k a_{\text {lymph }}}{k a_{\text {lym }}-C L / V d}\right.\right.} \\
& \left.\cdot\left(e^{-t \cdot C L / V d}-e^{-t \cdot k a_{l y m}}\right)\right) \\
& +\left(\frac{f_{\text {portal }} \cdot k a_{\text {portal }}}{k a_{\text {portal }}-C L / V d}\right. \\
& \left.\left.\cdot\left(e^{-t \cdot C L / V}-e^{-t \cdot k a_{\text {portal }}}\right)\right)\right]
\end{aligned}
$$

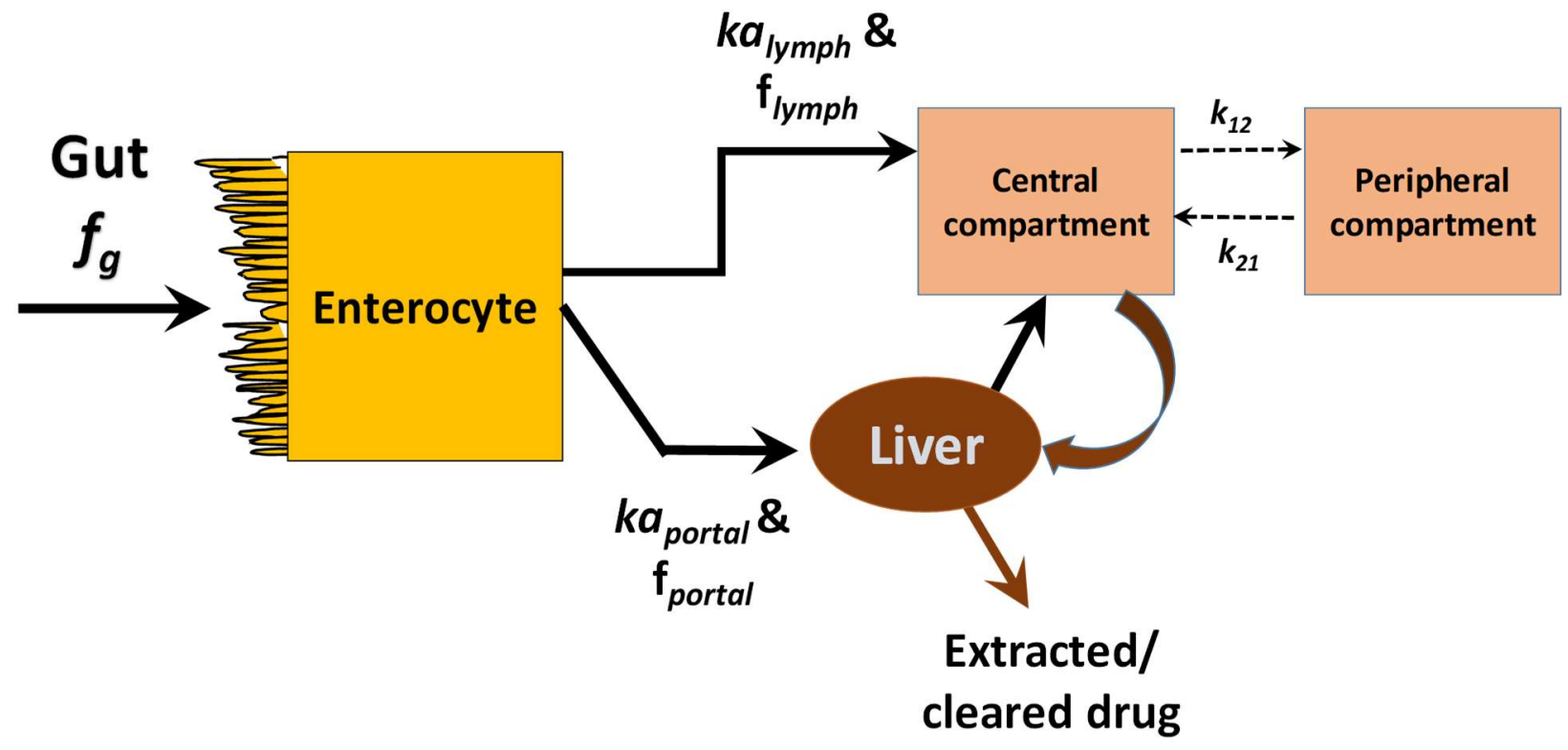

Figure 2. Two compartment model with dual pathway for drug systemic uptake. The fraction available to the gut, $f_{g}$, was assumed to be complete $\left(f_{g}=1\right)$ in all simulations. Each of the portal and lymphatic pathways has an absorption rate constant $(\mathrm{ka})$ and fraction $(f)$ term (where $f_{g}=f_{\text {lymph }}+f_{\text {portal }}$ ). The first order rate constants for transfer of drug movement between compartments are shown as $k_{12}$ and $k_{21}$. For the one compartment model, the peripheral compartment and intercompartmental rate constants are omitted. 
For the two-compartment model, the equation was as follows:

$$
\begin{aligned}
& C_{\text {blood }}=\frac{\text { Dose } \cdot k_{21}}{V c} \\
& \times\left[\left[f_{l y m p h} \cdot k a_{l y m}\right.\right. \\
& \cdot\left(\left(\frac{e^{-k a_{l y m}} \cdot t}{\left(\lambda_{1}-k a_{l y m p h}\right) \times\left(\lambda_{2}-k a_{l y m p}\right)}\right)+\left(\frac{e^{-\lambda_{1} \cdot t}}{\left(k a_{l y m p h}-\lambda_{1}\right) \times\left(\lambda_{2}-\lambda_{1}\right)}\right)\right. \\
& \left.\left.+\left(\frac{e^{-\lambda_{2} \cdot t}}{\left(k a_{l y m p}-\lambda_{2}\right) \times\left(\lambda_{1}-\lambda_{2}\right)}\right)\right)\right] \\
& +\left[f_{\text {portal }} \cdot k a_{\text {portal }}\right. \\
& \cdot\left(\left(\frac{e^{-k a_{\text {portal }} \cdot t}}{\left(\lambda_{1}-k a_{\text {portal }}\right) \times\left(\lambda_{2}-k a_{\text {portal }}\right)}\right)+\left(\frac{e^{-\lambda_{1} \cdot t}}{\left(k a_{\text {portal }}-\lambda_{1}\right) \times\left(\lambda_{2}-\lambda_{1}\right)}\right)\right. \\
& \left.\left.\left.+\left(\frac{e^{-\lambda_{2} \cdot t}}{\left(k a_{\text {portal }}-\lambda_{2}\right) \times\left(\lambda_{1}-\lambda_{2}\right)}\right)\right)\right]\right]
\end{aligned}
$$

In this model, $\mathrm{Vc}$ is the volume of the central compartment, $k_{21}$ is the first order constant describing rate of transfer from peripheral tissues to the central compartment, and $\lambda_{1}$ and $\lambda_{2}$ are the macro rate constants describing the decline in blood concentrations.

After absorption and transit across the enterocytes, two potential scenarios can occur including drug entry into blood capillaries and the other where entry into the lymph capillaries occurs. The pathway in which absorbed drugs pass directly into portal blood, has been the most prominently studied and/or assumed. This is reasonable considering its large rate of blood flow ( $\sim 500$ times) compared to that of the intestinal lymphatic flow ${ }^{11}$ However, many large and/or high molecular weight drugs are not readily able to readily diffuse across the blood capillaries. For other smaller-sized molecule drugs, high lipophilicity may provide for strong interactions with fatty components as they are being processed for lymphatic secretion from the enterocytes. Thus, these types of drugs represent possible good candidates for absorption via lymphatic capillaries.
Lymphatic transport begins with blind-ended vessels (lymph capillaries) found in tissues that create a capillary system in which lymph is drained $^{11,12}$. Lymph capillaries are highly permeable and are not pressurized allowing the lymph fluid to drain easily from the tissue into the lymph capillaries. The lymph vessels form a network throughout the body, and thus function in a unidirectional manner allowing the lymph to be drained from the tissues to the systemic blood. The subclavian blood vessels and the thoracic lymph duct join at the juncture of the left internal jugular and left subclavian veins, where their contents combine just prior to entry into the heart ${ }^{3,13,14}$.

Upon entry into the intestinal enterocyte, forming lipoproteins (mostly chylomicrons) are critical as they may potentially sequester highly lipophilic drugs ${ }^{2,15}$. This may facilitate movement from the enterocyte to the lymph. Indeed, lymphatic passage of drug into the lymph would normally require that the drug be incorporated into chylomicrons formed inside of the enterocytes ${ }^{2}$. Hence, it is a reasonable assumption that the rate of chylomicron and triglyceride appearance into the 
lymph and subsequently blood is linked to the rate of drug entry into the same fluids where lymphatic drainage is involved in drug absorption.

Based on reports examining fat absorption and entry into the lymph following ingestion of fats, it is apparent that there may be a lag time for the passage of fats into lymph and/or blood after ingestion of oral lipids. This is true in humans ${ }^{16,17}$, rats $^{18-21}$ and sheep $^{22}$. In each case, there is evidence of a lag time (of up to $3 \mathrm{~h}$ ) until lipid concentrations noticeably increase in lymph or plasma. Therefore, in the models used, an option of a lag-time was also introduced into the lymphatic absorption component (Figures 1 and 2). In order to obtain reasonable estimates of lymphatic absorption some published reports of fat absorption into the mesenteric lymph in cannulated animals ${ }^{18,22,23}$ were digitally scaled and the log amounts remaining to be passed into lymph were plotted versus time. This provided for estimates of lymphatic absorption rate constants. The total concentrations of drug in the circulating blood are the sum of the drug entering from each of the two pathways, as is depicted in Figure 3.

\section{Pharmacokinetic scenarios}

Hepatic metabolized drugs are characterized by their liver extraction ratio, E, calculated as $\frac{C L_{\text {int }}^{\prime}}{C L_{\text {int }}^{\prime}+Q}$ or $\frac{C L_{\text {hepatic }}}{Q}$. The extraction ratio $(E)$ of the liver as an organ of elimination is a measure of the organ's relative efficiency in eliminating the drug from the systemic circulation upon each pass through the $\operatorname{organ}^{24}$. An extraction ratio close to 0 indicates that most of the drug escapes elimination during a single pass through the organ. An $E$ close to 1 indicates that most of the drug is eliminated during a single pass through the organ. Drugs are often classified in three categories, low $(E<0.3)$, moderate $(E=0.3-0.7)$ and high $(E>0.7)$. The $C L$ of low $E$ drugs is highly dependent upon the product of $C L^{\prime}$ int and $f_{u}$. For high $E$ drugs, $C L$ is highly sensitive to changes in $Q$. The $C L$ of moderate $E$ drugs is influenced by changes in any of $C L_{i n t,}^{\prime}, f_{u}$ or $Q^{24}$.

Thus, in order to understand the influence of extraction ratio on lymphatic absorption three classes of hypothetical drugs were constructed, varying in the extent of hepatic extraction. One was low $(\mathrm{E}=0.1)$, one was moderate $(E=0.5)$ and the last one was high $(E=0.9)$. The fraction of the drug absorbed via the lymphatic route $\left(f_{\text {lymph }}\right)$ was then varied for each drug in increments ranging from $0\left(f_{\text {portal }}=1\right)$ to $1\left(f_{\text {portal }}=0\right)$. The volume of distribution $(V d)$ was set to 50 or $100 \mathrm{~L}$ for each drug. The $k a_{\text {lymph }}$ was set to $0.33 \mathrm{~h}^{-1}$ based on the average determined from analysis of fraction of fats being absorbed into lymph vs time as mentioned above. As there is no extra processing needed within the enterocytes for drug entry into the mesenteric blood, the $k a_{\text {portal }}$ was set to a higher value of $1 \mathrm{~h}^{-1}$.

For simplicity, it is assumed that the entire dose gains access to the enterocytes, and that there is no intestinal metabolism occurring.

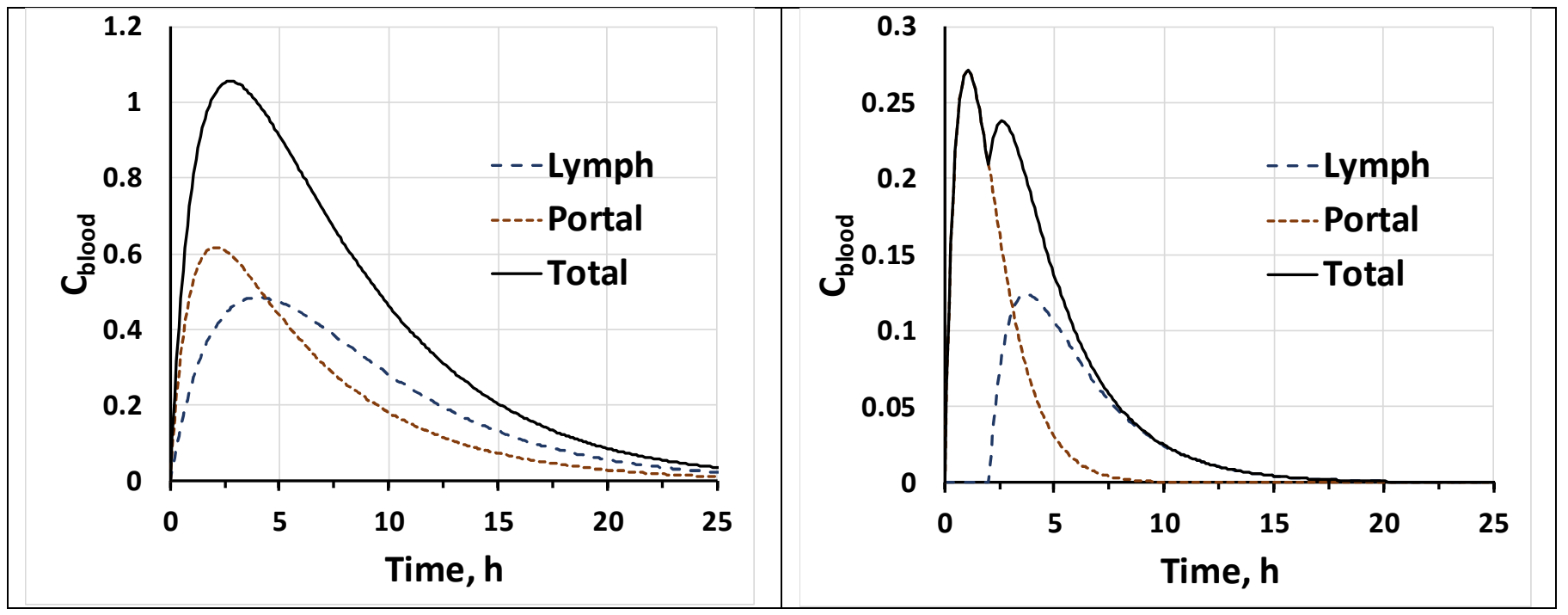

Figure 3. Depiction of blood concentrations of drug $\left(\mathrm{C}_{\text {blood }}\right)$ vs. time when the drug enters the body via the portal and lymphatic routes. Each pathway has its own concentration vs. time profile, with the total measured concentrations being the sum of drug at each time point from each pathway $\left(\mathrm{C}_{\text {blood }}=\right.$ lymph+portal contribution $)$. Panels show representative drugs in the absence (left) and presence (right) of a lag time. 


\section{Lymphatic absorption with no absorption lag} time

The results of these simulations are presented in Figures 4 and 5 for a one and two compartment model, respectively.

Both the one and two compartmental open model simulations showed similar trends in the effects on the blood concentration versus time profiles and in the resultant pharmacokinetic parameters. For a low $E$ drug, there were increases in tmax, decreases in Cmax, but negligible changes in overall drug exposure (AUC) with increases in $f_{\text {lymph }}$. For a moderate $\mathrm{E}$ drug, there was a doubling in the AUC from $f_{\text {lymph }}=0$ to $f_{\text {lymph }}$ of 1 , increase in tmax, but virtually no change in Cmax. The increase in AUC with increases in $f_{\text {lymph }}$ became highly pronounced with a high $E$ drug ( $>10$-fold), along with significant increases in Cmax and modest increases in tmax.

\section{Introduction of a lag time for lymphatic absorption}

Based on available studies where intestinal lymphatic uptake of drug was directly measured in the lymph of lymph-duct cannulated animals, there appears to be a lag time associated with appearance of drug and lipids into the lymph. It is also conceivable that a lag time might be associated with a fatty meal being eaten at some time after the ingestion of the dose, while the drug was still present in the gastrointestinal tract. Therefore, to explore the effects of a lag time on concentration vs. time profiles, two lag times of 1.5 and $3 \mathrm{~h}$ were introduced into the two compartment model drugs.

The simulation showed that if the fractions of the dose passing by the lymphatics and portal vein are kept constant, the AUC will not vary between situations where different lag times are present. However, there will be changes in the shapes of the concentration vs time curves and in the Cmax and tmax values as the lag time changes. A striking phenomenon that becomes apparent in the profile is the appearance of double peaking phenomena during the absorption phases (Figure 6). This becomes apparent and more pronounced as either of the following occurs: a.) the $f_{\text {lymph }}$ increases, b.) the hepatic extraction ratio increases, c.) the $t_{\text {lag }}$ increases. In some cases, there are clear secondary peaks whereas in others there is partial resolution of the peaks or shoulders appearing in the main peak.

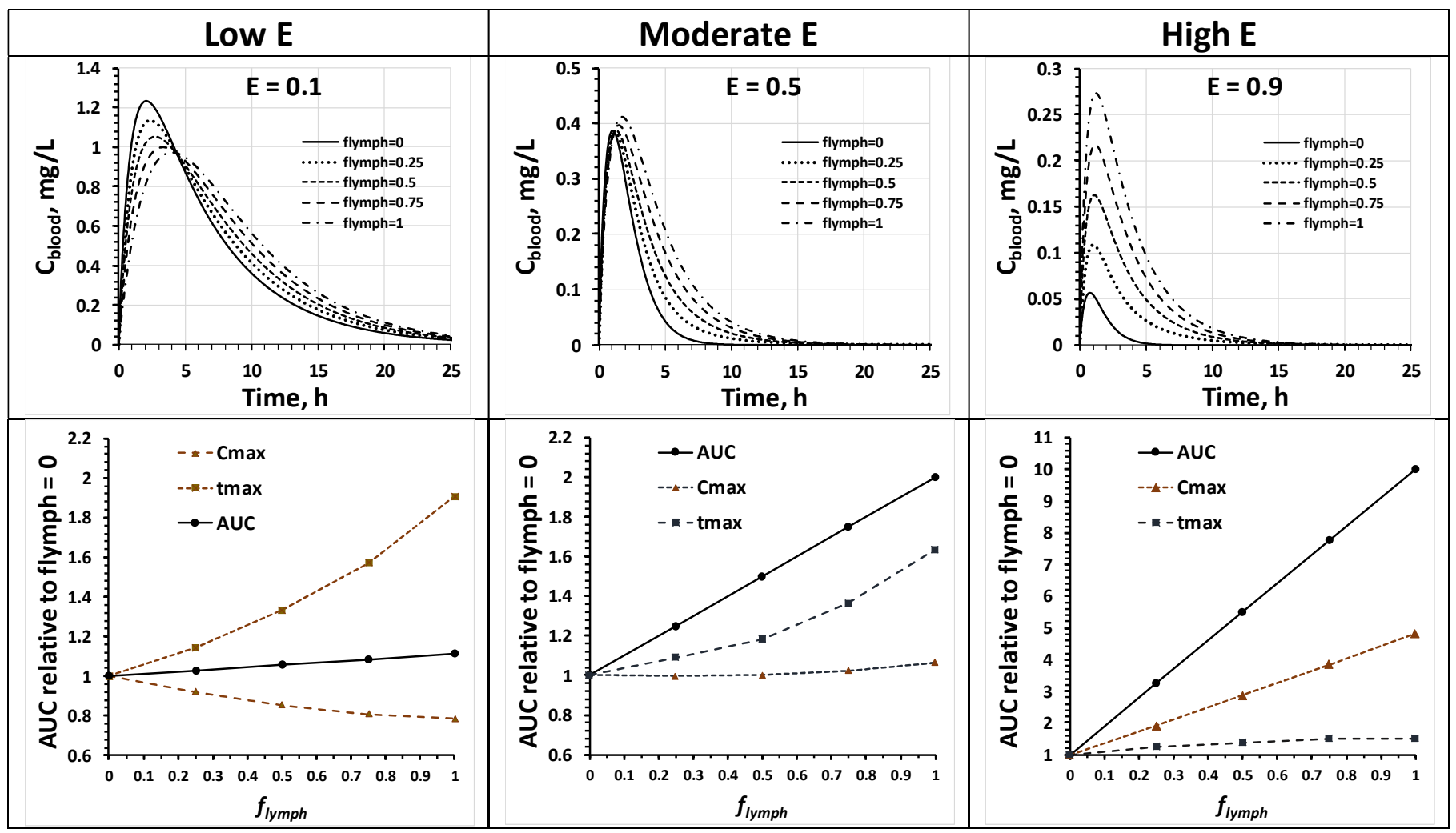

Figure 4. Concentration vs. time profiles for drugs following a one compartment model with low $(E=0.1)$, moderate $(E=0.5)$ and high $(E=0.9)$ levels of hepatic extraction over varying fractions of drug entering by the lymphatic routes. The $V d$ was set to $50 \mathrm{~L}$ and dose $100 \mathrm{mg}$. 


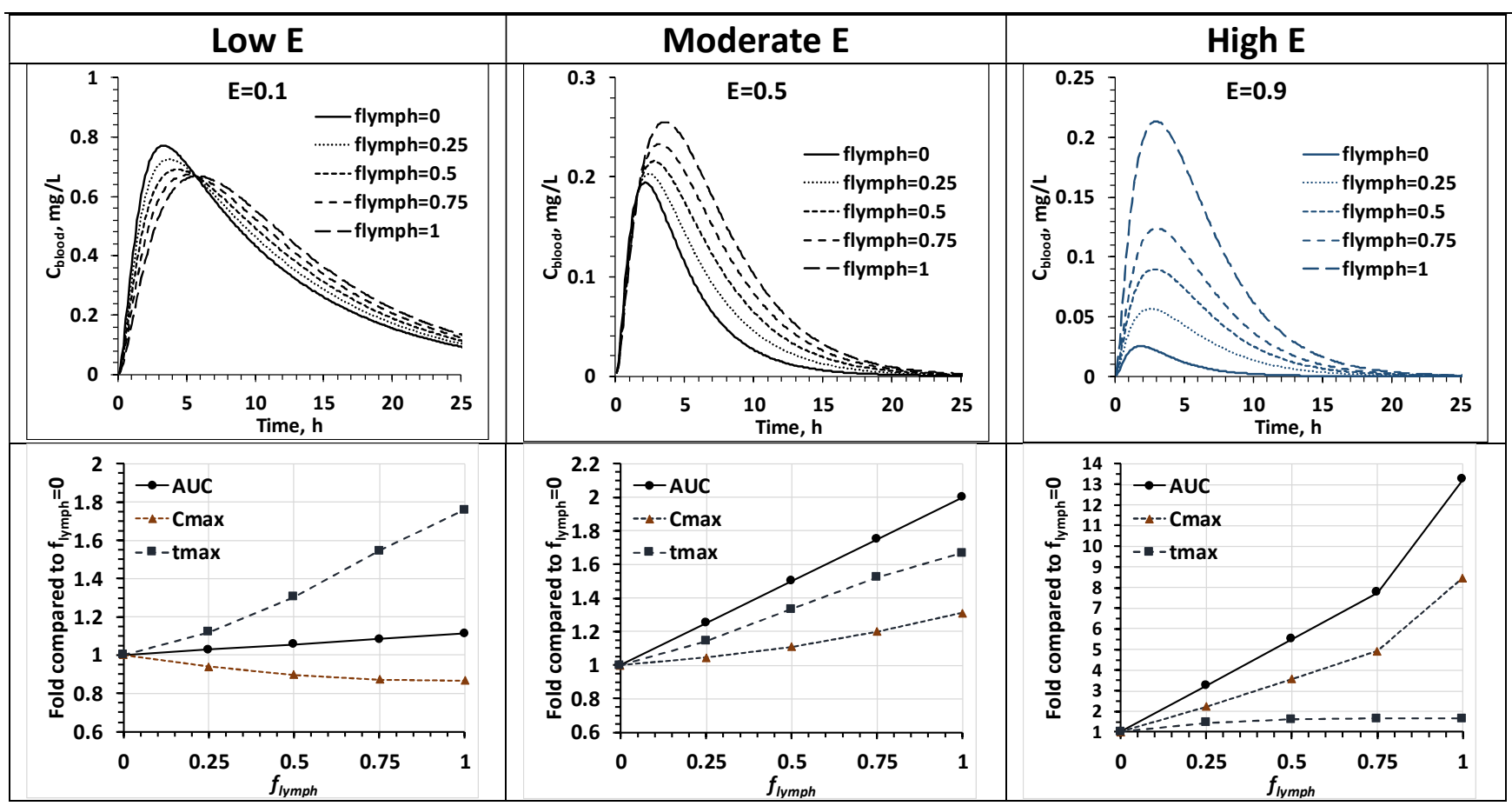

Figure 5. Concentration vs. time profiles for drugs following a two compartment open model with low $(E=0.1)$, moderate $(E=0.5)$ and high $(E=0.9)$ levels of hepatic extraction over varying fractions of drug entering by the lymphatic routes. Dose was set to $100 \mathrm{mg}$ and the $V c$ was set to $25 \mathrm{~L}$.

A lymphatic absorption module with a lag time option has been added to the instructional program uSIMPK $^{25}$ for the one compartment model as described above. The findings are similar to what was observed for the two compartment model (Figure 5).

\section{Competing lymph and portal uptake and influence of a lag time}

The above simulations assumed that the amount of drug entering from lymph and portal pathways retained a constant fraction of drug movement into the blood regardless of the lag time. In effect, if set to 0.5 each, half of the total dose was moved through each pathway independent of the presence of a lag time. It is possible that the two pathways compete for drug uptake however. In this case, for comparative purposes, let us assume that one case has no lag time for lymphatic absorption. For others, let us assume that there is a lag time of up to $3 \mathrm{~h}$. This may be due to an intrinsic delay in drug entry into the lymphatics as part of the chylomicron formation and drug incorporation steps in the enterocytes, or perhaps a meal eaten sometime after administration of the drug. After the meal, chylomicron formation is expected to be heavily promoted by intestinal processing of the fatty components in the meal. This would simultaneously be expectedly to promote intestinal lymphatic processing of lipophilic drugs into chylomicrons, which then would be passed into lymph. Thus, lymphatic entry of such drugs is dependent upon the availability of dietary lipids. For the no lag time situation, the entire dose is immediately available for fractional movement into the circulation via both portal and lymphatic pathways. For the lag time, however, prior to the meal the $f_{\text {lymph }}$ is essentially zero. By the time the meal in eaten, much of the dose may have already been absorbed via the portal route. Only after the meal was taken might the two fractions of $\mathrm{f}_{\text {lymph }}$ and $\mathrm{f}_{\text {portal, }}$ and their respective $k a$ values, be relevant. Furthermore, only the amount of dose remaining in the gastrointestinal tract once the meal is ingested is subject to both pathways of uptake.

This lag time and competing lymph and portal uptake scenario has been simulated here using the one compartment open model. The amount of dose remaining in the gastrointestinal tract up to the lag time is estimated as follows:

$$
\text { Dose }_{\text {remaining }}=\text { Dose } \cdot e^{-k a_{\text {portal }} \cdot t}
$$

Previous to this point in time where lymphatic absorption would occur $\left(t_{\text {lag }}\right)$, the available drug 
within the intestinal tract would be absorbed only by the portal pathway. Once the lymphatic pathway starts to contribute to absorption, the drug remaining in the intestinal tract would become subject to both the lymphatic and portal uptake processes.

For a low E drug, it becomes apparent that the introduction of a lag time (Figure 7) for lymphatic absorption has little impact on the AUC. The tmax is reduced as the lag time is prolonged, and the Cmax is increased, but no secondary peaks are visible in the profiles unlike the case where the ratio of lymph to portal uptake is kept constant (Figure 6 center left panel). Essentially, in this case, the proportion of the drug left in the intestines by the time the lymphatic route begins to proceed is much the same as if there was only portal absorption throughout. The expected increase in tmax and lowered Cmax caused by the slower rate of lymphatic absorption is apparent.

For a moderate $\mathrm{E}$ drug, the Cmax is negligibly affected, but the tmax is slightly decreased with a lag time (Figure 7). The overall AUC is also lower as the lag time is increased, but reaches a nadir with a lag time of $3 \mathrm{~h}$. In this case, more of the drug that has passed into the portal circulation has been cleared and extracted by the time the lymphatic pathway starts to proceed, which explains the reduced AUC compared to no lag time. As with the low E drug example, the concentration vs. time relationship appears as a single peak regardless of the presence of a lag time. This is in stark contrast to the observations where there is no competition for the pathways, where there is a secondary peak clearly present with the introduction of a lag time (Figure 6 center panel).

For a high E drug with competing lymphatic and portal absorption mechanisms, the effects of introducing a lag time are much more pronounced. It is apparent that the Cmax and AUC both fall precipitously and in parallel as the lag, time is increased. Like the moderate $\mathrm{E}$ drug, each approaches a nadir by $3 \mathrm{~h}$. Introducing a lag time allows a greater extent of the eventually absorbed drug mass to be subject to first pass extraction and hepatic CL before the lymphatic route commences.

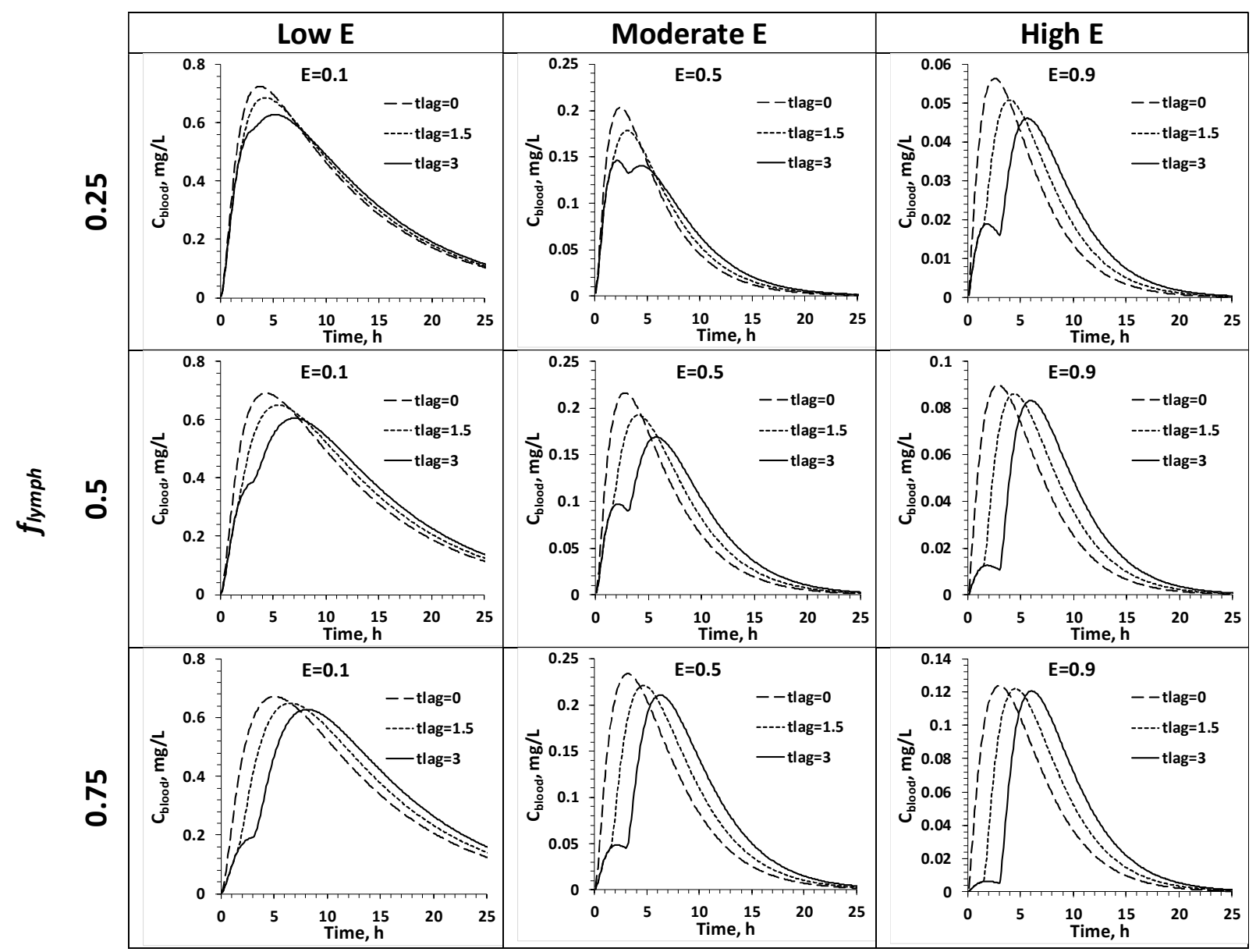

Figure 6. Effect of lag time for a drug following two compartments (see Figure 5) where the fraction of the dose passing into the lymphatic pathway is kept constant at $0.25,0.5$ or 0.75 . 
The tmax interestingly increases then decreases as $t_{\text {lag }}$ is increased, and unlike the low and moderate E drugs, in the concentration vs. time plots, double peaks become apparent with increased duration of lag time. Once the secondary peak becomes visible at $t_{\text {lag }}$ of $30 \mathrm{~min}$, the size of the secondary peak is initially larger than the first peak, but this ultimately switches with the use of longer lag times. Longer $t_{\text {lag }}$ results in drug concentration vs. time profiles that begin to resemble a situation where only portal absorption of drug is occurring with an absence of tlag (Figures 4 and 5).

\section{Effects of lipoprotein binding}

The role of fat absorption and transport is a major functional component of the lymphatic system. The lymphatic uptake of some drugs (which are lipophilic) is prone to be closely linked with the absorption of fats ${ }^{20}$. It is also not coincidental that many agents reportedly subject to lymphatic absorption $^{26-30}$ are also known to be highly bound to plasma proteins, including lipoproteins ${ }^{31-35}$. Thus, the uptake of fats by the intestinal lymphatic system might not only be associated with an increase in drug passage by this pathway, but also a transient increase in binding of drugs to lipoproteins as the lipids make their way into the blood. This will have an influence on the volume of distribution of the drug, and for hepatically cleared drugs, their magnitudes of $\mathrm{CL}$ and first pass extraction.

The main lipoprotein formed in the enterocytes that pass into the lymph are chylomicrons, which are the largest and least dense lipoproteins, mostly composed of triglyceride. Using the data presented for the post-prandial plasma triglyceride concentrations ${ }^{17}$, we digitized the profile and used it to gain an estimate of the rate of absorption and decline in blood. Any pre-meal values were subtracted from each value. Simulations using a onecompartment model assuming first order absorption and decline was applied using non-linear regression to minimize the sum of squares for the difference between reported and predicted values. Two first order rate constants were derived (one indicating increase and the other decrease in concentrations). The optimal rate constants for the processes were found to be $0.55 \mathrm{~h}^{-1}$ and $0.33 \mathrm{~h}^{-1}$. The prediction was improved with the inclusion of a lag time of $1 \mathrm{~h}$, but for the simulations we assumed no lag time.

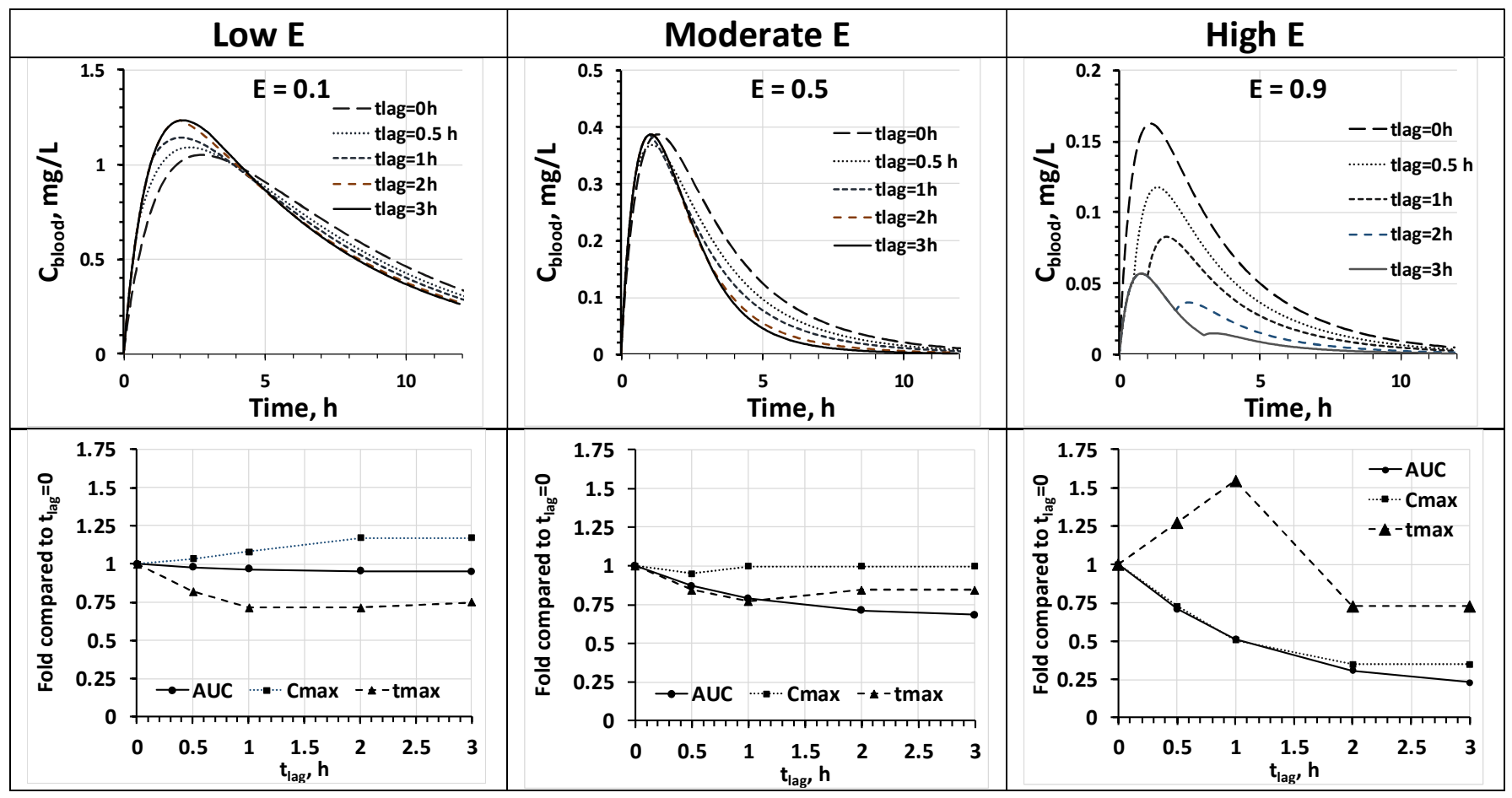

Figure 7. Concentration vs. time profiles for drugs following a one compartment model with low $(\mathrm{E}=0.1)$, moderate $(\mathrm{E}=0.5)$ and high $(E=0.9)$ levels of hepatic extraction over varying lag times of drug entering by the lymphatic routes. The dose was $100 \mathrm{mg}$ and the $\mathrm{Vd}$ was set to $50 \mathrm{~L}$. 


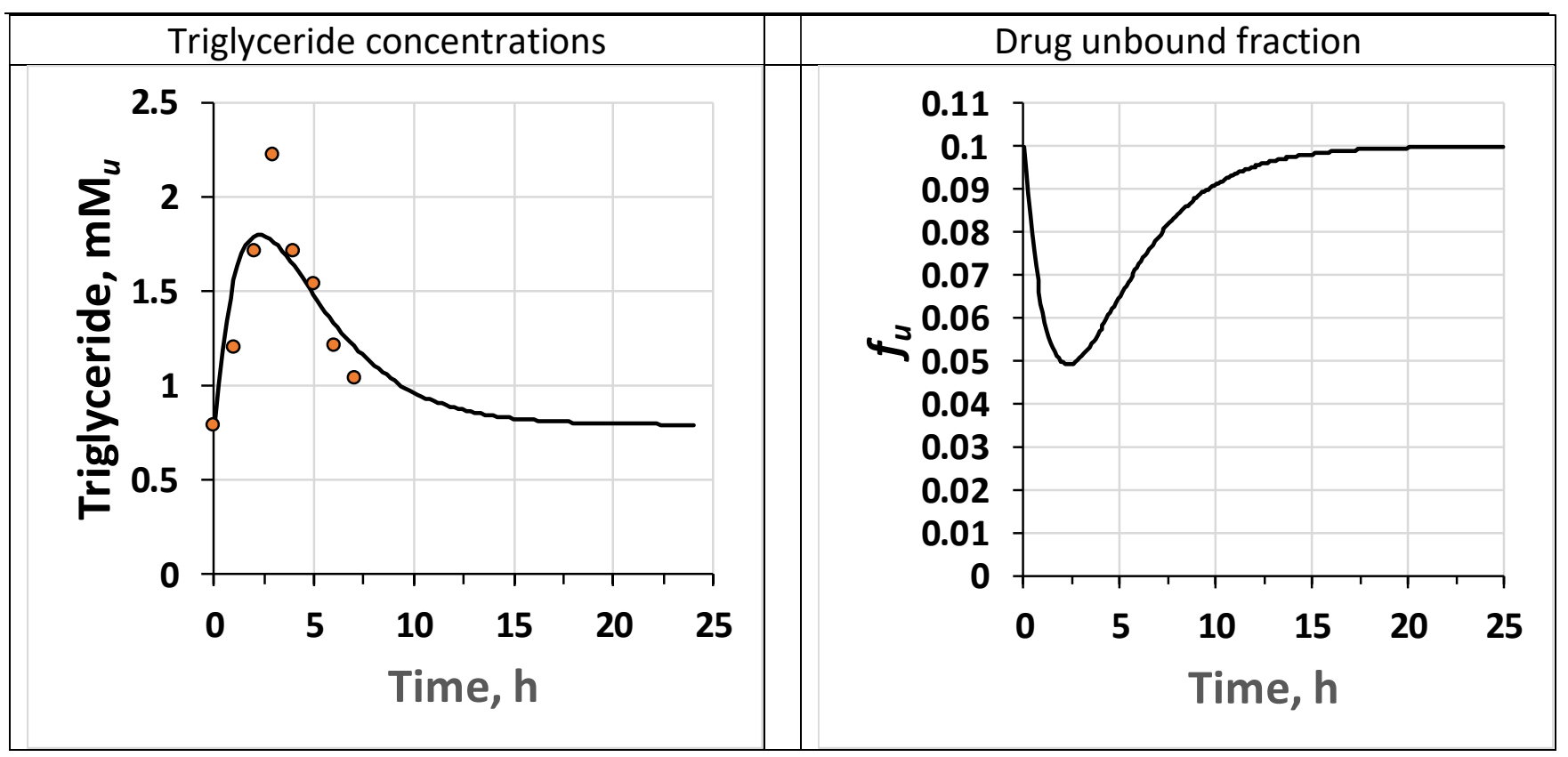

Figure 8. The simulated plasma triglyceride vs. time relationship (solid line, with data from Rifai et al ${ }^{17}$ ) and the resultant simulated unbound concentrations in blood (left panel) vs. time curve (solid line). The right panel depicts the changes in unbound fraction of drug in blood $\left(f_{u}\right)$ assuming a starting fasted fu of 0.1 and maximal decrease in $f_{u}$ to 0.05 .

These values were used to simulate the changes in plasma protein binding such that the unbound fraction would arbitrarily decrease by a maximum factor of two as the triglyceride concentrations increased to their peak. Thereafter, the values would return to the initial fasted basal condition. These $f_{u}$ values were then applied to three hypothetical hepatically cleared drugs that each followed a onecompartment model, differing in their degrees of hepatic extraction. Each drug was modelled as if it were given in the fasted state (where the $f_{u}$ remained constant at 0.1 ), or where a meal was given, lipids absorbed and lipoprotein binding changing such that the $f_{u}$ transiently decreased by half, then gradually rebounding back to the original 0.1 value as shown in Figure 8. These changes in unbound concentrations were then applied to the administrations of low, moderate and high E drugs in the presence and absence of a meal, which would promote lymphatic absorption. In addition to the total (bound + unbound) blood drug concentrations, the unbound concentrations were also determined by multiplying the total concentration by the $f_{u}$ at each time point. These simulations were performed in the absence of a lag time for lymphatic absorption. One could view this as either the meal being ingested along with the administration of the dose, or in the case of a lag time, just before the dose such that the uptake of lipids via the lymphatic route coincided with the administration of the oral dose of drug. The $f_{\text {portal }}$ were progressively decreased from $1\left(f_{\text {lymph }}=0\right)$ to $0\left(f_{\text {lymph }}=1\right)$ to examine the influence of lymphatic absorption.

\section{Total drug blood concentrations}

For all administrations with low and moderate E drugs, compared to fasted conditions, administration of the meal led to increases in the AUC of the total drug concentrations in blood (Figures 9 and 10). There was a slight and essentially negligible increase in this ratio of fed to fasted AUC as the $f_{\text {lymph }}$ increased for these drugs. The Cmax and tmax for these drugs followed a similar pattern of increases as the $f_{\text {lymph }}$ increased, where Cmax was well over one for the fed state throughout and tmax starting at less than one then slightly increasing to the point where $f_{\text {lymph }}$ was 1.

Compared to lower levels of hepatic extraction, the high E drug behaved somewhat differently under fed and fasted conditions as the $f_{\text {lymph }}$ increased. For each of the AUC, Cmax and tmax parameters, there was little relative change in the parameters until the $f_{\text {lymph }}$ accounted greater than $50 \%$ of the absorption pathway. The rise was greater as the $f_{\text {lymph }}$ approached a value of 1 . 


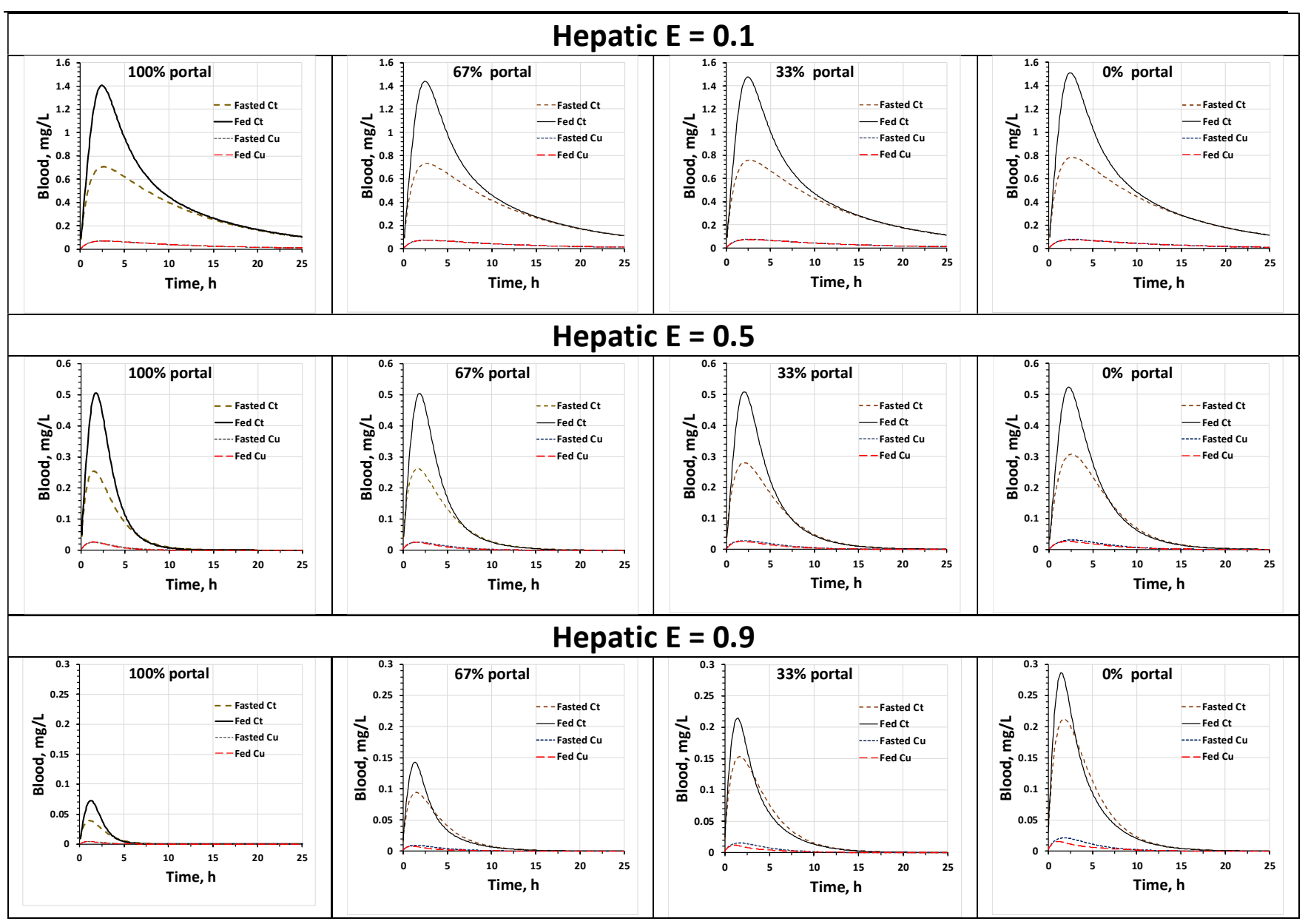

Figure 9. Blood concentration vs. time curves for lipoprotein-bound drugs of varying hepatic extraction ratio with $\mathrm{f}_{\text {lymph }}$ and $\mathrm{f}_{\text {portal }}$ kept at $50 \%$ each, administered with and without a meal. Simulations used a one compartment model. The unbound fractions for fasted conditions were maintained at 0.1 , whereas after the meal the $f_{u}$ changes according to that presented in Figure 8. The dose was $100 \mathrm{mg}$ and the initial $\mathrm{Vd}$ was set to $100 \mathrm{~L}$ (where $V_{\text {blood }}=4.9 \mathrm{~L}$ and $V_{\text {app,tissues }}$ was $95.1 \mathrm{~L}$ ).

The effect of increasing the fraction of $f_{\text {lymph }}$ on total drug AUC was most noticeable on the moderate and low E drugs, where there were steady increases in AUC as the $f_{\text {lymph }}$ increased and $f_{\text {portal }}$ decreased (Figure 11). This was not seen for the low E drug. In all classes of drugs with $\mathrm{E}$ ranging from 0.1 to 0.9 , the fed state had higher AUC than the matching fasted state for that level of hepatic E.

\section{Unbound drug concentrations}

For most drugs, it is the unbound drug concentration that is able to traverse cell membranes and interact with tissue receptors for drug action; hence it unbound drug is considered the pharmacologically and toxicologically active component of total drug in the blood. The examination of the systemic exposure for the unbound drug revealed some important differences depending on the magnitude of hepatic $\mathrm{E}$ (Figures 9 to 11).

For the low E drug, although in the presence of food the total drug AUC and Cmax were consistently $>1$ throughout the spectrum of lymphatic vs. portal uptake (Figure 10), there was virtually no difference (fed to fasted ratio 1) in the AUC (Figure 11) and Cmax of the unbound drug concentrations (Figure 12). For the moderate and high $\mathrm{E}$ drugs, the ratios of unbound AUC and Cmax of fed compared to fasted states were both less than one when the $f_{\text {lymph }}$ was highest. As the portal pathway became more prevalent, though, the ratio of fed to fasted AUC and Cmax increased to values of near one.

Increasing the $f_{\text {lymph }}$ had the effect of increasing the AUC of pharmacologically active unbound drug compared to lower levels of $f_{\text {lymph }}$ (Figure 11). 
However, the rise in AUC was higher for the fasting than the post-prandial state.

\section{Synopsis of simulation results}

There have been, and continue to be, attempts made to improve the oral bioavailability of new chemical entities and drugs by formulating drug products that can promote the lymphatic absorptive pathway of drug entry into the systemic circulation through enterocytes. At the same time, there has been little emphasis on the understanding of the critical pharmacokinetic aspects of lymphatic drug delivery. If a drug could only attain systemic availability solely through the lymphatic pathway, then hepatic extraction would never be an issue. A singular lymphatic absorption pathway could be possible through a targeted ligand delivery approach for lower size (100-200 nM) drugs and vaccines to be transcytosed by $M$ cells in Peyers patches in the intestine for absorption through the intestinal lymphatics that bypasses the liver ${ }^{11}$. In such a case, efforts to increase lymphatic uptake through $\mathrm{M}$ cells rather than enterocytes could be an additional approach to increasing drug absorption and may have further utility for vaccine, protein, and peptide absorption.

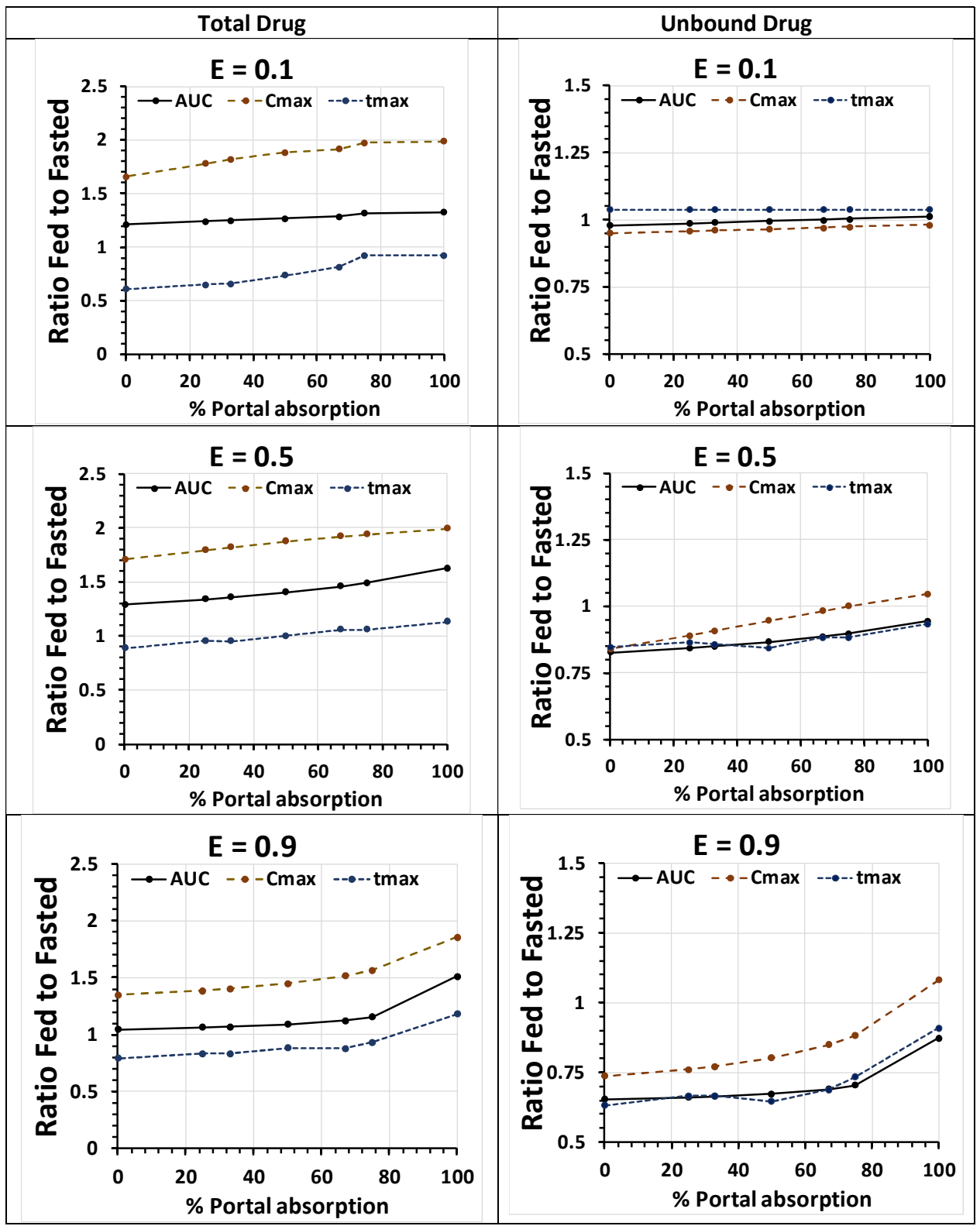

Figure 10. Changes in AUC, Cmax and tmax for the low, moderate and high E drugs administered with and without a meal (from data depicted in Figure 9). 


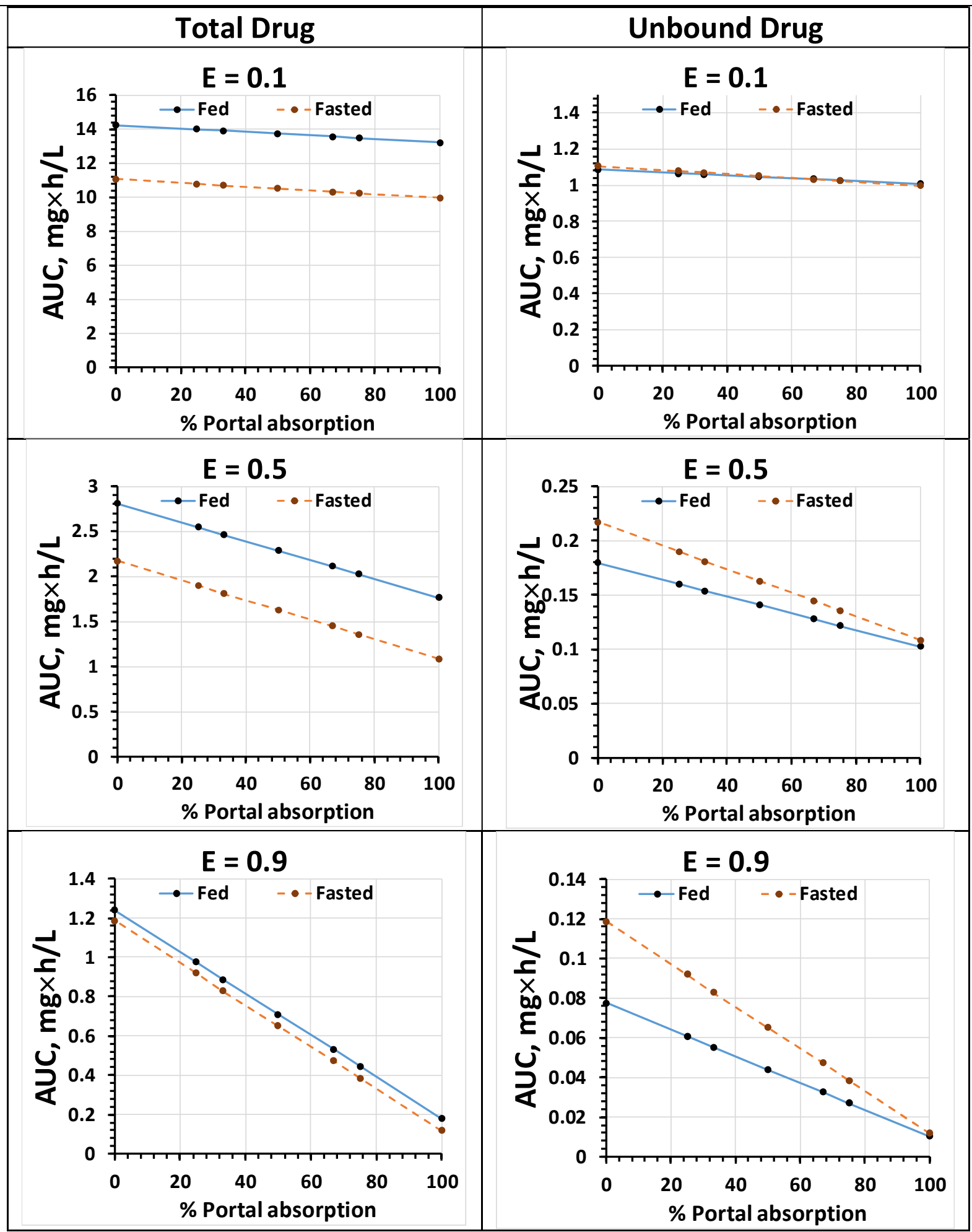

Figure 11. The blood AUC from the data presented in Figures 9 and 10 where transiently increased protein binding occurs in the post-prandial vs. the fasted states.

It seems unlikely that for most small molecules passing into lymph from the enterocytes, that additional portal uptake would not occur. Although many investigators have presented data showing concentration of drugs in lymph after lymphatic mesenteric and/or thoracic duct cannulation and 
diversion, few have also shown the blood fluid concentrations in doing so and comparing them to non-cannulated animals. In the few studies that have, it is apparent that drug still appears in the blood fluids after cannulation. This suggests that the portal pathway is still involved in drug absorption. This is further supported by studies where chemical inhibitors of intestinal chylomicron inhibition have been employed, where concentrations of drug can still appear in the blood. In such cases, one has to consider the combined effects of both pathways, which is what we have done in these simulations, and which can be performed using a new USIMPK module.

The simulations show that the impact of lymphatic absorption on the blood concentrations is heavily reliant on a number of factors, most notably, the magnitude of the drug's hepatic extraction. Drugs that have a low hepatic extraction ratio are not expected to have any therapeutic advantage in diversion of the drug mass away from the portal pathway into the lymph pathway. Increases in concentrations will only be achieved for those drugs that possess a hepatic extraction ratio of greater than 0.3 . As we have shown, the introduction of a lag time for absorption may result in double peaks during the absorption phase, which are most noticeable for those drugs with hepatic extraction ratios $>0.3$. To our knowledge, the role of lymphatic absorption has not been recognized previously as to its mechanistic contribution to this pharmacokinetic phenomena ${ }^{36}$. However, we have noted many examples of concentration-time curves of drugs reported to undergo lymphatic absorption showing double peaking or multiple peaking phenomena in the literature ${ }^{26,37-45}$. When competition for absorption occurs between the portal and lymphatic pathways in combination with a lag time, the summation of the two first-order absorption processes can lead to the double peaking phenomena becoming most notable for those drugs which have a hepatic extraction ratio $>0.7$.

In the event that plasma protein binding increases due to the effect of increased drug binding to the lipoproteins introduced after a high fat meal, increases in total drug concentrations may occur irrespective of the extent of hepatic extraction in response to the meal (Figures 9 to 11). However, for a low E drug, there will be no changes expected in the magnitude of the unbound drug concentration between the fasted and fed states. In effect, even though the total concentrations are increased, to maintain the level of drug effect, there will be no need to decrease the dose level, irrespective of the fraction of the dose entering via the lymphatics. On the other hand, for moderate and especially high $\mathrm{E}$ drugs, higher levels of $f_{\text {lymph }}$ will be associated after a meal with lower concentrations of unbound drug, even though the total concentrations are greater in the post-prandial state. Therapeutically, therefore, a drug with high $\mathrm{E}$ and high $f_{\text {lymph }}$ may have lower levels of pharmacological effect after a high fat meal than under fasted conditions. When the $f_{\text {portal }}$ increases to near 1 , however, the fed:fasted ratio of unbound AUC approaches a value of unity because bioavailability by the portal pathway is increased due to the smaller unbound fraction during the period of drug absorption. Therapeutically, therefore, when the portal pathway becomes predominant, a given dose level under fasted or fed conditions will provide similar levels of pharmacological effect (in our simulations only 13\% lower unbound drug AUC when $f_{\text {portal }}=1$ compared to $35 \%$ lower when $f_{\text {lymph }}=1$ ). Shunting a high E drug to lymphatics, therefore, would be most successful by giving the drug under fasted conditions if the drug is subject to decreases in unbound fraction. As the simulations show, any increase in plasma protein binding associated with the meal will partially blunt the increase in unbound concentration caused by shunting the drug to the lymphatic route (Figure 11 bottom right panel).

In the pharmacokinetic simulations, we assumed that the rate of drug entry via the portal route is faster than that of the lymphatic pathway, because for lymphatic uptake drug must be incorporated first into chylomicrons within the enterocytes. For this reason, in many of the simulations a "flip-flop" phenomenon was apparent in the terminal phase, where the negative slope of the terminal part of the concentration vs. time curve was reflective of the speed of lymphatic absorption rather than drug elimination. Hence, we recognize that lymphatic absorption also has the capability of leading not only to double peaks ${ }^{17}$, but also can be an underlying factor in the "flip-flop" phenomenon ${ }^{46}$.

\section{Limitations and caveats}

Not all scenarios could be included in the current models. Our main focus was on those drugs mainly eliminated by the liver, usually by metabolism. Some drugs may undergo enterohepatic recycling, and/or other pathways of CL such as renal. The influence of other extrahepatic CL mechanisms would not likely affect oral bioavailability but would obviously 
contribute to the CL of the drug. This would lead to a lower AUC if added to hepatic CL. In regards to biliary recycling, this would lead to additional secondary peaks, but if it were to occur, it would not be expected to favor either the portal or lymphatic pathways appreciably. In essence, it would likely have the same impact on AUC as a general reduction in drug CL.

Other factors not incorporated into the simulations are possible effects of saturation of the lymphatic pathway and intestinal transporters. Although it is conceivable that one of the steps in chylomicron formation is saturable, this occurrence would likely be mitigated by the relatively small mass of drug typically given, in conjunction with the vast length and surface area afforded by the gastrointestinal tract for drug absorption. Indeed, the intestinal tract is designed for optimal absorption of nutrients including fats. The intestinal lymphatic system is also not static but rather adaptive to ingestion of lipids, by decreasing lymphatic pump function, increasing lymph flow, triglyceride concentration and viscosity ${ }^{47}$.

Intestinal transporters present on the mucosal aspect of enterocytes would have the effect of changing the amount of drug mass entering into the enterocyte, but not changing the relative outcomes of lymphatic vs. portal contributions to absorption. If on the serosal aspect, however, transporters might conceivable change the balance of lymphatic vs. portal absorption, which should be considered. Intestinal drug metabolism would lower bioavailability but is not expected to change the balance of drug entering via the lymphatic and portal routes.

One last limitation of the simulations is based on the data used to estimate the $k a_{l y m p h}$. This value was derived from cannulated animals, something that would be difficult to do in humans. Thus, there is some uncertainty as to what the value might be in humans.

\section{CONCLUSION}

The utility of in silico pharmacokinetic simulation and modeling has highlighted important considerations and factors that should be carefully considered during rationale design, development and formulations of drugs if lymphatic absorption is being considered $a b$ initio in the process.

\section{ACKNOWLEDGMENT}

Tyson Le for assistance with illustration of the liver.

\section{REFERENCES}

1. Trevaskis NL, Charman WN, Porter CJ 2008. Lipidbased delivery systems and intestinal lymphatic drug transport: a mechanistic update. Adv Drug Deliv Rev 60(6):702-716.

2. Wasan KM, Brocks DR, Lee SD, Sachs-Barrable K, Thornton SJ 2008. Impact of lipoproteins on the biological activity and disposition of hydrophobic drugs: implications for drug discovery. Nat Rev Drug Discov 7(1):84-99.

3. Yanez JA, Wang SW, Knemeyer IW, Wirth MA, Alton KB 2011. Intestinal lymphatic transport for drug delivery. Adv Drug Deliv Rev 63(10-11):923942.

4. Hosea NA, Jones HM 2013. Predicting pharmacokinetic profiles using in silico derived parameters. Mol Pharm 10(4):1207-1215.

5. Leahy DE 2006. Integrating in vitro ADMET data through generic physiologically based pharmacokinetic models. Expert Opin Drug Metab Toxicol 2(4):619-628.

6. Dahan A, Hoffman A 2005. Evaluation of a chylomicron flow blocking approach to investigate the intestinal lymphatic transport of lipophilic drugs. Eur J Pharm Sci 24(4):381-388.

7. Holm R, Porter CJ, Mullertz A, Kristensen HG, Charman WN 2002. Structured triglyceride vehicles for oral delivery of halofantrine: examination of intestinal lymphatic transport and bioavailability in conscious rats. Pharm Res 19(9):1354-1361.

8. Lespine A, Chanoit G, Bousquet-Melou A, Lallemand E, Bassissi FM, Alvinerie M, Toutain PL 2006. Contribution of lymphatic transport to the systemic exposure of orally administered moxidectin in conscious lymph duct-cannulated dogs. Eur $\mathrm{J}$ Pharm Sci 27(1):37-43.

9. Trevaskis NL, Shackleford DM, Charman WN, Edwards GA, Gardin A, Appel-Dingemanse S, Kretz O, Galli B, Porter CJ 2009. Intestinal lymphatic transport enhances the post-prandial oral bioavailability of a novel cannabinoid receptor agonist via avoidance of first-pass metabolism. Pharm Res 26(6):1486-1495.

10. Davies B, Morris T 1993. Physiological parameters in laboratory animals and humans. Pharm Res 10(7):1093-1095.

11. Managuli RS, Raut SY, Reddy MS, Mutalik S 2018. Targeting the intestinal lymphatic system: a versatile path for enhanced oral bioavailability of drugs. Expert Opin Drug Deliv 15(8):787-804.

12. Breslin JW 2014. Mechanical forces and lymphatic transport. Microvasc Res 96:46-54. 
13. Negrini D, Moriondo A 2011. Lymphatic anatomy and biomechanics. J Physiol 589(Pt 12):2927-2934.

14. Reddy NP 1986. Lymph circulation: physiology, pharmacology, and biomechanics. Crit Rev Biomed Eng 14(1):45-91.

15. Porter CJ, Trevaskis NL, Charman WN 2007. Lipids and lipid-based formulations: optimizing the oral delivery of lipophilic drugs. Nat Rev Drug Discov 6(3):231-248.

16. Cohn JS, Johnson EJ, Millar JS, Cohn SD, Milne RW, Marcel YL, Russell RM, Schaefer EJ 1993. Contribution of apoB-48 and apoB-100 triglyceriderich lipoproteins (TRL) to postprandial increases in the plasma concentration of TRL triglycerides and retinyl esters. J Lipid Res 34(12):2033-2040.

17. Rifai N, Merrill JR, Holly RG 1990. Postprandial effect of a high fat meal on plasma lipid, lipoprotein cholesterol and apolipoprotein measurements. Ann Clin Biochem 27 ( Pt 5):489-493.

18. Porsgaard T, Hoy CE 2000. Lymphatic transport in rats of several dietary fats differing in fatty acid profile and triacylglycerol structure. J Nutr 130(6):1619-1624.

19. Porsgaard T, Straarup EM, Hoy CE 1999. Lymphatic fatty acid absorption profile during 24 hours after administration of triglycerides to rats. Lipids 34(2):103-107.

20. Trevaskis NL, Hu L, Caliph SM, Han S, Porter CJ 2015. The mesenteric lymph duct cannulated rat model: application to the assessment of intestinal lymphatic drug transport. J Vis Exp (97).

21. Windmueller HG, Spaeth AE 1972. Fat transport and lymph and plasma lipoprotein biosynthesis by isolated intestine. J Lipid Res 13(1):92-105.

22. Heath TJ, Morris B 1962. The absorption of fat in sheep and lambs. Q J Exp Physiol Cogn Med Sci 47:157-169.

23. Kalogeris TJ, Fukagawa K, Tso P 1994. Synthesis and lymphatic transport of intestinal apolipoprotein A-IV in response to graded doses of triglyceride. J Lipid Res 35(7):1141-1151.

24. Mehvar R 2018. Clearance Concepts: Fundamentals and Application to Pharmacokinetic Behavior of Drugs. J Pharm Pharm Sci 21(1s):88s-102s.

25. Brocks DR 2015. uSIMPK. An Excel for Windowsbased simulation program for instruction of basic pharmacokinetics principles to pharmacy students. Comput Methods Programs Biomed 120(3):154-163.

26. Attili-Qadri S, Karra N, Nemirovski A, Schwob O, Talmon Y, Nassar T, Benita S 2013. Oral delivery system prolongs blood circulation of docetaxel nanocapsules via lymphatic absorption. Proc Natl Acad Sci U S A 110(43):17498-17503.

27. Dahan A, Mendelman A, Amsili S, Ezov N, Hoffman A 2007. The effect of general anesthesia on the intestinal lymphatic transport of lipophilic drugs: comparison between anesthetized and freely moving conscious rat models. Eur J Pharm Sci 32(4-5):367374.

28. Fidge NH, Shiratori T, Ganguly J, Goodman DS 1968. Pathways of absorption of retinal and retinoic acid in the rat. J Lipid Res 9(1):103-109.

29. Takada K, Furuya Y, Yoshikawa H, Muranishi S 1988. Biological and pharmaceutical factors affecting the absorption and lymphatic delivery of ciclosporin A from gastrointestinal tract. J Pharmacobiodyn 11(2):80-87.

30. Trevaskis NL, Caliph SM, Nguyen G, Tso P, Charman WN, Porter CJ 2013. A mouse model to evaluate the impact of species, sex, and lipid load on lymphatic drug transport. Pharm Res 30(12):32543270.

31. Blaner WS, Li Y, Brun PJ, Yuen JJ, Lee SA, Clugston RD 2016. Vitamin A Absorption, Storage and Mobilization. Subcell Biochem 81:95-125.

32. Patel JP, Hamdy DA, El-Kadi AO, Brocks DR 2012. Effect of serum lipoproteins on stereoselective halofantrine metabolism by rat hepatocytes. Chirality 24(7):558-565.

33. Speeckaert MM, Taes YE, De Buyzere ML, Christophe AB, Kaufman JM, Delanghe JR 2010. Investigation of the potential association of vitamin $\mathrm{D}$ binding protein with lipoproteins. Ann Clin Biochem 47(Pt 2):143-150.

34. Urien S, Zini R, Lemaire M, Tillement JP 1990. Assessment of cyclosporine A interactions with human plasma lipoproteins in vitro and in vivo in the rat. J Pharmacol Exp Ther 253(1):305-309.

35. Urien S, Barre J, Morin C, Paccaly A, Montay G, Tillement JP 1996. Docetaxel serum protein binding with high affinity to alpha 1 -acid glycoprotein. Invest New Drugs 14(2):147-151.

36. Davies NM, Takemoto JK, Brocks DR, Yanez JA 2010. Multiple peaking phenomena in pharmacokinetic disposition. Clin Pharmacokinet 49(6):351-377.

37. Elsheikh MA, Elnaggar YSR, Hamdy DA, Abdallah OY 2018. Novel cremochylomicrons for improved oral bioavailability of the antineoplastic phytomedicine berberine chloride: Optimization and pharmacokinetics. Int J Pharm 535(1-2):316-324.

38. Ghassemi S, Haeri A, Shahhosseini S, Dadashzadeh S 2018. Labrasol-Enriched Nanoliposomal Formulation: Novel Approach to Improve Oral Absorption of Water-Insoluble Drug, Carvedilol. AAPS PharmSciTech.

39. Li F, Hu R, Wang B, Gui Y, Cheng G, Gao S, Ye L, Tang J 2017. Self-microemulsifying drug delivery system for improving the bioavailability of huperzine A by lymphatic uptake. Acta Pharm Sin B 7(3):353360.

40. Lind ML, Jacobsen J, Holm R, Mullertz A 2008. Intestinal lymphatic transport of halofantrine in rats assessed using a chylomicron flow blocking 
approach: the influence of polysorbate 60 and 80 . Eur J Pharm Sci 35(3):211-218.

41. Makwana V, Jain R, Patel K, Nivsarkar M, Joshi A 2015. Solid lipid nanoparticles (SLN) of Efavirenz as lymph targeting drug delivery system: Elucidation of mechanism of uptake using chylomicron flow blocking approach. Int J Pharm 495(1):439-446.

42. Ravi PR, Aditya N, Kathuria H, Malekar S, Vats R 2014. Lipid nanoparticles for oral delivery of raloxifene: optimization, stability, in vivo evaluation and uptake mechanism. Eur J Pharm Biopharm 87(1):114-124.

43. Sun M, Zhai X, Xue K, Hu L, Yang X, Li G, Si L 2011. Intestinal absorption and intestinal lymphatic transport of sirolimus from self-microemulsifying drug delivery systems assessed using the single-pass intestinal perfusion (SPIP) technique and a chylomicron flow blocking approach: linear correlation with oral bioavailabilities in rats. Eur $\mathrm{J}$ Pharm Sci 43(3):132-140.

44. Tang TT, Hu XB, Liao DH, Liu XY, Xiang DX 2013. Mechanisms of microemulsion enhancing the oral bioavailability of puerarin: comparison between oil- in-water and water-in-oil microemulsions using the single-pass intestinal perfusion method and a chylomicron flow blocking approach. Int $\mathrm{J}$ Nanomedicine 8:4415-4426.

45. Xing Q, Song J, You X, Xu D, Wang K, Guo Q, Li P, $\mathrm{Wu} \mathrm{C}, \mathrm{Hu} \mathrm{H}$ 2016. Microemulsions containing longchain oil ethyl oleate improve the oral bioavailability of piroxicam by increasing drug solubility and lymphatic transportation simultaneously. Int J Pharm 511(2):709-718.

46. Yanez JA, Remsberg CM, Sayre CL, Forrest ML, Davies NM 2011. Flip-flop pharmacokinetics-delivering a reversal of disposition: challenges and opportunities during drug development. Ther Deliv 2(5):643-672.

47. Kassis T, Yarlagadda SC, Kohan AB, Tso P, Breedveld V, Dixon JB 2016. Postprandial lymphatic pump function after a high-fat meal: a characterization of contractility, flow, and viscosity. Am J Physiol Gastrointest Liver Physiol 310(10):G776-789. 